\title{
Pelvic packing or endovascular interventions: which should be given priority in managing hemodynamically unstable pelvic fractures? A systematic review and a meta-analysis
}

\author{
Dong Zhang \\ the Fourth Medical Center of PLA General Hospital \\ Gong-zi Zhang \\ the First Medical Center of PLA General Hospital \\ Ye Peng \\ the First Medical Center of PLA General Hospital \\ Shu-wei Zhang \\ the First Medical Center of PLA General Hospital \\ Meng Li \\ the Fourth Medical Center of PLA General Hospital \\ Yv Jiang \\ the Fourth Medical Center of PLA General Hospital \\ Li-hai Zhang ( $\nabla$ zhanglihai74@qq.com ) \\ the First Medical Center of PLA General Hospital
}

\section{Research Article}

Keywords: Pelvic fracture, Hemodynamically unstable, Hemorrhage, Pelvic packing, Endovascular intervention, Angiography-embolization, Resuscitative endovascular balloon occlusion of the aorta

Posted Date: February 28th, 2022

DOI: https://doi.org/10.21203/rs.3.rs-1394526/v1

License: @ (i) This work is licensed under a Creative Commons Attribution 4.0 International License. Read Full License 


\section{Abstract}

Background: Pelvic fractures in trauma patients can be associated with substantial massive hemorrhage. Mainly hemostasis interventions consist of pelvic packing (PP) and endovascular intervention (EI), such as angiography-embolization (AE) and resuscitative endovascular balloon occlusion of the aorta (REBOA). Whether PP or El should be given priority for the management of hemodynamic unstable patients with pelvic fractures is still under debate. This meta-analysis aims to find out the evidence-based recommendations to fill the gap in literature.

Materials and Methods: PubMed, CENTRAL, and EMBASE was searched for articles published from Jan $1^{\text {st }}, 2000$ to Jan $31^{\text {st }}, 2022$. Eligible studies, such as retrospective cohort study, propensity score matching studies, prospective cohort study, observational cohort study, quasi-randomized clinical trial evaluating PP and El (AE or REBOA) managing patients with hemodynamically unstable pelvic fractures, were included. Mean Difference (MD), relative risk (RR), and 95\% confidence intervals $(\mathrm{Cl})$ were calculated employing fixed- or random-effects models depending on the heterogeneity of included trials. This meta-analysis was performed to compare the effectiveness of the two methods in terms of mortality, unstable fracture pattens, Injury Severity Score (ISS), systolic blood pressure (SBP), lactate (LA), base deficiency (-BE), hemoglobin preoperatively, blood transfusion requirement, the time to and of operation, the complications.

Results: 15 trials enrolling 1,136 patients were analyzed with the total mortality of $28.4 \%(323 / 1136)$. In our study, there was no effect of PP preference on the

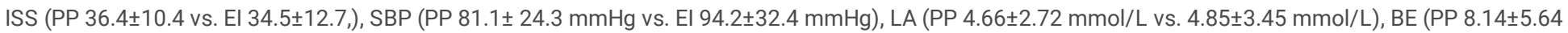
$\mathrm{mmol} / \mathrm{L}$ vs. $6.66 \pm 5.68 \mathrm{mmol} / \mathrm{L})$, unstable fracture pattens $(\mathrm{RR}=1.10,95 \% \mathrm{Cl}[0.63,1.92])$. The application of PP was associated with lower preoperative hemoglobin level(PP $8.11 \pm 2.28 \mathrm{~g} / \mathrm{dl}$ vs. El $8.43 \pm 2.43 \mathrm{~g} / \mathrm{dl}, \mathrm{p}<0.05)$, more preoperative transfusion( $\mathrm{MD}=2.53,95 \% \mathrm{Cl}[0.01,5.06])$, less postoperative transfusion within first 24 hours(MD=-1.09, 95\% $\mathrm{Cl}[-1.96,-0.22])$, shorter waiting time to intervention( $\mathrm{MD}=-0.93,95 \% \mathrm{Cl}[-1.54,-0.31])$, shorter operation time of intervention( $\mathrm{MD}=-0.41,95 \% \mathrm{Cl}[-0.52,-0.30])$. PP has lower mortality rate due to uncontrolled hemorrhage in the acute phase (RR= $0.41,95 \% \mathrm{Cl}[0.22,0.79])$. There is neither difference on mortality due to other complications ( $R R=1.60,95 \% \mathrm{Cl}[0.79,3.24])$, nor total mortality $(\mathrm{RR}=0.92,95 \% \mathrm{Cl}[0.49,1.74])(p>0.05)$.

Conclusions: We firstly reached a conclusion that PP, a reliable hemostatic method, had advantages of reducing the amount of postoperative transfusion, shortening the time of waiting and operating and decreasing the mortality due to uncontrolled hemorrhage in the acute phase, without raising the odds of mortality due to complications. PP should be given a high priority in resuscitating the most pelvic fractures with hemodynamically unstable, especially in case of bleeding from veins and fracture sites, as well as inadequate El. Sometimes AE should be regarded as a complementary treatment in case of the relative stable branch artery injury, the recurrent hypotension and ongoing hypotension after PP. REBOA is recommended in temporally transporting the hemorrhagic shock patients and stopping fatal bleeding from the main artery or multiple-sources.

\section{Background}

Approximately $3 \%-6 \%$ of patients with pelvic injuries, mostly resulting from high-energy accidents such as road traffic crashes and falls, are hemodynamically unstable. Exsanguinating hemorrhage is identified as the leading cause of death during the first $48 \mathrm{~h}$ after injury, with mortality remaining at approximately 1/3[1-3]. Multi-organ failure (MOF), sepsis and acute respiratory distress syndrome (ARDS) contribute to the majority of deaths thereafter[2]. Hemorrhaging from pelvis mainly originates from iliac arterial branches, the presacral venous plexus, and cancellous bone[4].

Management of hemodynamically unstable pelvic fractures remains a challenging task and involves a coordinated multidisciplinary approach using all types of resuscitative methods. Although multiple studies[5-7] have reported that emergent external fixation and pelvic C-clamp are quick and effective against lowpressure bleeding by restoring the pelvic volume and limiting motion between the fractured bone surfaces, the Eastern Association for the Surgery of Trauma did not highly recommend emergent external fixation and pelvic C-clamp in controlling hemorrhage due to the lack of enough clinical trials[8].

Pelvic packing (PP, including preperitoneal and retroperitoneal pelvic packing), effective in controlling bleeding from veins and fractured cancellous bone surfaces, is widely advocated to rapidly arrest hemorrhage. Endovascular intervention (EI), such as angiography-embolization (AE) and resuscitative endovascular balloon occlusion of the aorta (REBOA), recent years has been successfully used in hemostatic resuscitation[9]. Early angiography and subsequent embolization or balloon occlusion help to stop the arterial bleeding and displays a significant improvement in survival rate[10,11] .

Obviously, the choice of which intervention should be firstly utilized mainly depends on the exact source of hemorrhage, however the bleeding source is sophisticated and difficult to detect especially when pelvic fractures are in the context of a polytrauma. Many studies have made an attempt to correlate fracture patterns with blood loss and the source of bleeding, unfortunately these is not a tendency conclusion[12, 13]. These all interventions are essential for the multidisciplinary management and indispensable for resuscitate patients with hemodynamically unstable pelvic fractures. Many surgeons refer PP since simple and quick[1, 2, 14, 15], the other hand some surgeons believe El is effective and minimal invasive[11, 16, 17]. However, the priority intervention remains controversial among orthopedists[6, 18]. Hotspot as it is, most of patients with life-threatening pelvic fracture have been died before hospital, so the incidence rate of these patients in emergency department of level-I trauma center is very low. In addition, the hemodynamics unstable pelvic fractures are stochastic and unpredictable. The deficiency of sample population and the difficulty of randomized clinical trial retards its judgment in choosing the intervention and hinds its development. Beyond that, convincing, detailed data comparing these interventions are lacking; thus, there are few high-quality reviews and well-quantity analyses. To date, there has been only one review analyzing PP and AE, but it failed to show the superiority of either treatment[19]. Despite insufficient studies, the high mortality rate in clinical practice urged us to figure out an evidence-based consensus.

As the priority intervention for controlling fatal bleeding in patients with hemodynamically unstable pelvic fractures is still under debate, this study, which provides new insights that may be used to make such determinations. As a result, we tried to perform a systematic review and meta-analysis and made best use of evidence available. 
The study aimed to figure out which protocol can more significantly reduce the mortality in the acute phase (the definition varies among different trauma centers, usually < 48 hours, and the cause of death is mainly attributed to uncontrolled hemorrhage), the mortality due to other complications (such as MOF, sepsis and ARDS) [20] and the total mortality; investigate the difference between these interventions on fracture patterns (relatively stable and unstable fractures as below), Injury Severity Score (ISS), systolic blood pressure (SBP), lactate (LA), base deficiency (-BE), hemoglobin preoperatively and postoperatively, blood transfusion requirement, and the time to and of operation. Tai believed that in the Young-Burgess classification, Type LC-I, LC-II and APCI were minor injuries that were mechanically relatively stable fractures, and Type LC-III, APC-II, APC-III, VS and combined mechanism were major injuries that were mechanically unstable fractures[21]. The meta-analysis and systemic review have obtained ethics approval in our hospital.

\section{Materials And Methods}

\section{Search strategy}

An electronic search of the PubMed, CENTRAL, and EMBASE databases was performed for relevant studies published between Jan $1^{\text {st }} 2000$ and Jan $31^{\text {st }}$ 2022. Keywords used to identify relevant articles were "pelvic fracture" AND "hemorrhage" AND "angiography embolization" AND "packing". We used the MeSH terms, including "pelvis" or "Fractures, Bone" or "Shock, Traumatic" or "Hip Injuries" or "Multiple Trauma" or "Embolization, Therapeutic" or "Angiography" or "Endotamponade". We used the Emtree terms including "pelvis" or "fractures" or "wound" or "injury" or "traumatic shock" or "pelvis injury" or "multiple trauma" or "artificial embolism" or "pelvis angiography" or "endotamponade". We confined our results in humans and in studies published in English. The reference lists of the retrieved articles and relevant review papers were also examined for eligible papers. Certain quality criteria were clearly set before initiating the electronic literature search. Grey literature was also searched in Opengrey.

\section{Inclusion and exclusion criteria}

Our inclusion and exclusion criteria were specified in advance according to multiple parameters, including involved the population, relevant interventions, outcomes and the type of study.

\section{Inclusion criteria:}

1. The study population included pelvic fracture patients with hemodynamic instability defined as systolic blood pressure (SBP) $<90 \mathrm{mmHg}$ after administration of two units of packed red blood cells (PRBC) or $\geq 2000 \mathrm{~mL}$ of intravenous crystalloid

2. Clinical practice involves two protocols giving priority to separate approaches, PP and El (AE or REBOA), to control bleeding

3. A minimum of one outcome of interest was described

4. Randomized controlled trials, retrospective or prospective cohort studies, and case-control studies

\section{Exclusion criteria:}

1. Patients with other fatal injuries

2. Merely one intervention investigated in a study

3. Other types of interventions

4. Review articles, case reports, conference presentations, and epidemiological studies

5. Literature screen

6. Biomechanical or animal studies

A total of 216 articles were retrieved from the databases after the exclusion of duplicates. Two reviewers (ZD and ZGZ) independently evaluated titles and abstracts of all retrieved papers basing on inclusion and exclusion criteria, and the steps were presented in Fig.1. Any discrepancy between the two reviewers was resolved through discussion or consultation with a third reviewer (LM). To avoid duplication of data duplication, the search procedure was not blinded to the authors' names, trauma centers or journals. The names of authors of each study, the period of patient enrollment within each study and patient demographics were scrutinized and reviewed again to evaluate the eligibility of including relevant data to ensure that they met the inclusion criteria.

\section{Assessment of the methodological quality}

The Newcastle-Ottawa Quality Assessment Scale (NOS) has been prevalently applied to evaluate the methodological quality of non-randomized controlled trials. A final score of $\geq 7$ is considered as high quality. Individual studies were assessed according to NOS. Two authors (ZD and ZGZ) independently scored the studies. Differences were resolved by a discussion with a supervisor (JY) to achieve consensus.

\section{Data extraction}

Data were independently extracted by two individuals(ZD and ZGZ).Study characteristics were recorded as follows: the first author's name, publication year, study type, study period, patient characteristics (age, sex, ISS, SBP on admission, LA, BE, and fracture type), number of enrolled patients, total mortality, mortality attributed to uncontrolled hemorrhage in the acute phase, mortality due to MOF or sepsis, time to and of the intervention, the hemoglobin preoperatively and postoperatively, and the blood transfusion requirement. Data from individual studies was rechecked from the original papers by two reviewers (PY and ZSW).

\section{Meta-analyses}


All analyses were performed using Review Manager 5.3 (The Nordic Cochrane Centre, The Cochrane Collaboration, 2014) and Stata 12.0 (4905 Lakeway Drive College Station, 2011). Between-study heterogeneity was evaluated using the Chi-square-based Q statistic and regarded as statistically significant when heterogeneity $<0.1$ or $\mathrm{I}^{2}<50 \%$. A fixed-effects model was used (Mantel-Haenszel method) in the absence of heterogeneity. Otherwise, the results were analyzed using a random-effects model (Der Simonian-Larid method). Publication bias was evaluated by the funnel plot and Egger's test. Sensitivity analysis was performed with the one-study remove approach. The mainly effect measures are consist of mean difference, relative risks, odds ratios. The $95 \%$ confidence interval $(\mathrm{Cl})$ of the risk ratio to describe the significance of difference between interventions. A two-sided p-value $<0.05$ is considered statistically significant.

\section{Results}

\section{Systematic Literature Search}

After reviewing the full text, 15 studies met the inclusion criteria in the meta-analysis[3, 5, 21-33]. All studies had a low risk of bias for selective blinding.

All articles, reviewing patients from Apr. 1998 to Jan. 2019, were comparative in nature with 11 retrospective cohort studies (including two propensity score matching studies and one multicenter study), two quasi-randomized clinical trials, one observational cohort study and one prospective cohort study. All articles assessed by the NOS scale had a similar qualified design. As reported in Table 1, all studies met the criteria of high-quality study (range=7-8); therefore, they can be meta-analyzed.

\section{Basic characteristics of included patients}

Fifteen studies included a total of 1,136 patients with hemodynamically unstable pelvic fractures, approximately $37.3 \%$ (16.7\%-42.4\%) of whom were female. The mean age of individual study ranged from 10.0 to 62.5 years old, with $46.9 \pm 17.5$ years in the PP group and $48.7 \pm 17.4$ years in the El group. The average ISS of individuals ranged from 28 to 57.7 , and that of the separate group is $36.4 \pm 10.4$ and $34.5 \pm 12.7$ for PP and El, respectively. The average LA of the separate group ranged from 3.4 to $5.8 \mathrm{mmol} / \mathrm{L}$, with $4.66 \pm 2.72 \mathrm{vs} .4 .85 \pm 3.45 \mathrm{mmol} / \mathrm{L}$ for PP and El, respectively. The average BE of separate group ranged from 4.3 to $14.8 \mathrm{mmol} / \mathrm{L}$, with PP $8.14 \pm 5.64 \mathrm{vs}$. El $6.66 \pm 5.68 \mathrm{mmol} / \mathrm{L}$. The average SBP of separate group ranged from 68 to $120 \mathrm{mmHg}$, with PP $81.1 \pm 24.3$ $\mathrm{mmHg}$ vs. El $94.2 \pm 32.4 \mathrm{mmHg}$. There was no significant difference between the two groups in terms of age, ISS, LA, BE, SBP and unstable fracture patterns $(p>0.05)$. However, there is insufficient information on the heartrate, respiration rate, Glasgow score and postoperative hemoglobin to analyze. Detailed information is presented in Table 2.

\section{The results of the meta-analysis for transfusion before operation (MD)}

Transfusion is an imperative method to resuscitate patients and is an indispensable step within peri-operation. There were 10 studies comparing preoperative transfusion between PP and AE[3, 21, 22, 24-30] and two studies on PP and REBOA[31, 32] , which showed much more transfusion in PP group than in El group (MD=2.53, 95\% Cl [0.01, 5.06], Fig.3).

\section{The results of the meta-analysis for transfusion after operation in the first $24 \mathrm{~h}$ (MD)}

Osborn et al. reported a significant difference in the decrease of PRBCs transfused in the first $24 \mathrm{~h}$ after interventions[22]. However, that study didn't provide a standard deviation for further analysis. According to the data pooled across these five studies on PP vs. AE $[5,21,22,25,28]$ and two studies on PP vs. REBOA[31, 33], there was a significant difference between interventions ( $\mathrm{MD}=-1.09,95 \% \mathrm{Cl}[-1.96,-0.22]$, Fig.4). Furthermore, the subgroup analysis detected that El required more postoperative transfusion $(\mathrm{MD}=-0.98,95 \% \mathrm{Cl}[-1.87,-0.09])$.

\section{The results of the meta-analysis for waiting time to operation (MD)}

Time is an important factor affecting survival. Eight studies on PP vs. AE[5, 21, 22, 24-28] and three on PP vs. REBOA[31-33] reported the waiting time to operation, and the pooled data showed the waiting time in PP group was obviously shorter (PP $1.23 \pm 1.68$ hours vs. El $2.37 \pm 3.00$ hours, $\mathrm{MD}=-0.93,95 \% \mathrm{Cl}$ $[-1.54,-0.31]$, Fig.5).

\section{The results of the meta-analysis for the operation time of intervention (MD)}

The meta-analysis was conducted in 3 studies to assess the operation time of the procedures[21, 25, 31]. PP group has slightly shorter time (PP $0.92 \pm 0.20$ hours VS El $1.25 \pm 0.60$ hours, MD=-0.41, 95\% Cl [-0.52, -0.30], Fig. 6).

\section{The results of the meta-analysis for mortality due to uncontrolled hemorrhage in the acute phase (RR)}

The data for mortality in the acute phase were pooled across 10 studies on PP vs. AE[5, 21-28, 30]and 3 studies on PP vs. REBOA[31-33]. The mortality due to uncontrolled hemorrhage in the acute phase was 11.1\% (50/449) in PP group and 20.1\% (97/482) in El group. As displayed in Fig.7, the analysis of the data revealed a significant difference in mortality in the acute phase between these interventions ( $\mathrm{RR}=0.41,95 \% \mathrm{Cl}[0.22,0.79])$. Subgroup analysis showed a significant difference between the PP and El groups ( $R R=0.32,95 \% \mathrm{Cl}[0.17,0.60], \mathrm{p}=0.0003)$; however, no difference was found between the PP and REBOA groups ( $R R=0.54,95 \% \mathrm{Cl}[0.11,2.62], p=0.45)$. The result revealed a significant difference in mortality attributed to exsanguination, which required the $P P$ to reduce the mortailty.

\section{The results of the meta-analysis for mortality due to other complications (RR)}

The most common complications following pelvic fractures with unstable hemodynamics consist of MOF, infection or sepsis, ARDS, thrombosis, disseminated intravascular coagulation, bedsore, etc., and they threat the survival rate. These complications were also mentioned in these studies above [5, 
21-28, 30-33]. The mortality due to other complications was 17.8\% (80/449) in PP group and 12.6\% (61/482) in El group. In contrast, there was no difference between the two interventions ( $R R=1.60,95 \% \mathrm{Cl}[0.79,3.24], \mathrm{p}=0.06$, Fig.8).

\section{The results of the meta-analysis for total mortality (RR)}

The total mortality in our study was $28.4 \%$ (323/1,136), with $29.1 \%(155 / 533)$ PP vs. $27.9 \%(168 / 603)$ in the PP and El groups, respectively. When referring to the total mortality, as shown in Fig.9, data were pooled across 15 studies. The analysis also demonstrated no differences between these interventions $(\mathrm{RR}=0.92,95 \% \mathrm{Cl}[0.49,1.74]$, Fig.9). Nor significant difference was found in subgroup analysis( $p>0.05)$.

\section{Discussion}

Hemodynamically unstable pelvic fractures, the so-called "life-threatening injuries", are associated with high mortality and morbidity, always require a series of sequenced protocols and combined measures rather than only an intervention. Factors that affect the primary clinical decision-making in emergency depend on basic conditions (vital signs, Glasgow score, ISS, blood test and fracture classification), response to initial resuscitation, source of exsanguination, blood transfusion, medical infrastructure, endovascular intervention on call, the experience and habits of surgeons and the hospital facilities, and so on. We reviewed all these studies and attempted to analyze these data.

\section{Basic conditions of the patients upon admission.}

These basic conditions mainly consisted of SBP, heartrate, injury score (Glasgow score and ISS), blood gas analysis (LA and BE), hemoglobin, fracture types, and the source of exsanguination.

Hemodynamics-unstable patients had persistent hypotension ( $\mathrm{SBP}<90 \mathrm{mmHg}$ ) and anemia (hemoglobin $<120 \mathrm{~g} / \mathrm{L}$ ) in spite of loading $2 \mathrm{~L}$ of crystalloid and transfusion of two units of PRBCs[3], same as we found that PP $81.1 \pm 24.3 \mathrm{mmHg}$ and El $94.2 \pm 32.4 \mathrm{mmHg}$ in the meta-analysis ( $p>0.05$ ). There was inadequate shock data on heartrate, $\mathrm{SpO}_{2}$, respiration rates nor Glasgow score, neither blood coagulation analysis in these studies. Therefore, more welldesign trials with full data describing detailed hemodynamics are warranted.

Sandhu et al. found that these patients had metabolic acidosis resulting from poor circulation and sudden irritation after a high-energy injury. They concluded that serum lactate was higher and -BE was abnormal in non-survivors[3], which were similar to our obtained outcomes.

Marmor et al.[34] suggested that the Young and Burgess classification focusing on injury mechanism and severity degree were associated with the degree of blood loss, as well as increasing ISS. In our meta-analysis, we spotted that hemodynamically unstable pelvic fractures always had a high ISS of $>34$ and unstable fracture patterns $(56.9 \%, 357 / 627)$. In the literature, there is an increasing incidence of injury of thoracoabdominal organs, retroperitoneal hematoma, shock, sepsis, ARDS, and transfusion requirement as fracture pattern severity, especially in APC-II, APC-III, VS and combined injury types[3, 35]. Hak advised that an external fixator could be managed along with PP to treat mechanic-unstable pelvic injuries[36].

However, we did not get the statistics-based suggestion whether PP or El priority on fracture patterns (RR $=1.10,95 \% \mathrm{Cl}[0.63,1.92])$, neither ISS (PP $36.4 \pm$ 10.4 vs. El $34.5 \pm 12.7)(p>0.05)$.

Bleeding from the fractured bony surface, the pre-sacral and pre-vesical plexus happened in pelvic ring open-book injuries[11, 37], of which the mechanism might be stretching and tearing of the veins and arteries adjacent to the pelvis. CTA scan is the golden standard for diagnosis of the bleeding source and could be used to measure the size of a hematoma by dynamic observation[38].Moon et al. failed to determine that the fracture pattern was one of clinical predictors of El. However, Lee[39] suggested El could be used in hematoma at $>3.35 \mathrm{~cm}$ from the artery.

Apart from the a tiny difference in hemoglobin levels upon admission with $8.11 \pm 2.28 \mathrm{~g} / \mathrm{dl}$ vs. $8.43 \pm 2.43 \mathrm{~g} / \mathrm{dl}$ for PP and El, respectively, there were no significant differences on basic conditions between these interventions $(p>0.05)$; therefore, they are of comparability and can be included in the metaanalyses. As a result, the outcomes of our study are convincing.

\section{Blood transfusion.}

Transfusion has long been used to maintain vital signs and escort hemodynamically compensated pelvic fractures. Wong et al. reported that the risk of death would have increased by $62 \%$ for every 1 unit/h increase in transfusion need[40]. Hak recommended that at least six units of PRBCs within 4 hours were needed for hemodynamically unstable patients[36], accompanied by fresh frozen plasma and platelets in a 1:1:1 ratio to prevent early coagulopathy.

In our study, the requirement of the transfusion in the PP group was greater than that in the El group before surgery, but less than El group after surgery. The PP group showed a decrease in the amount of PRBCs transfused in the first $24 \mathrm{~h}$ compared with the El group, similar to the results of Osborn[22]. Yet, such decrease was not observed in the El group. We presumed two possible explanations: the first, PP indeed stopped bleeding efficiently; the second, massive preoperational transfusion played a part in reducing requirement of postoperative transfusion.

Furthermore, the PP group needed more transfusion before surgery $(\mathrm{MD}=2.53,95 \% \mathrm{Cl}[0.01,5.06])$, which might be due to other co-existing organ injuries accounting for hemorrhage in the PP group (one clue is PP group has slightly lower hemoglobin levels before operation), which requires the combination of PP and another kind of surgery. Based on the current evidence, we hypothesize that PP is more effective in decreasing the transfusion requirements than El. Nevertheless, more studies with larger population are still required to verify these findings. 
The total mortality rate and incidence of MOF significantly rose as the transfusion requirement for PRBCs increased[41].Consequently, to bring up the likelihood of survival, we need to curb the units of PRBCs. However, in the case of hypovolemic shock, sufficient transfusion is also necessary, which is very contradictory. That situation requires another quick and effective method to control bleeding. Fortunately, PP achieves a significantly lower mortality and decreases the units of transfusion.

\section{The Endovascular Intervention Department.}

The Endovascular Intervention Department contributes remarkably to restoring the lives of hemodynamically unstable patients. However, there are still several issues remain. Firstly, a well-built Endovascular Intervention Department and experienced doctors are lacking in some hospitals, but just now have been spreading and developing quickly[42]. Second, the protocols and preparation of Endovascular Intervention differing from day to night, from workday to weekend, usually needs more time for preparation[25]. Third, the embolization or occlusion site, techniques, experience, habit, equipment and consumable materials, the doctors' preference and habit vary significantly[37], of what reason El differ in different studies.

\section{The time to/of the operation.}

On the basis of Filiberto's research, PP was performed within 41 to 66 mins of arrival at the hospital[15]. However, El is a time-consuming procedure. The waiting time to undertake angioembolization has been reported to range from 50 minutes to 6.0 hours[43]. In our study, there was a significant increase in waiting time to intervention (PP: $1.23 \pm 1.68$ hours vs. El: $2.37 \pm 3.00$ hours) in the El group, due to the preparations and on-call protocols. Time is a fatal factor that influences the mortality in the management of hemodynamically unstable patients. The priority of El may delay the management of torrential venous bleeding (more than $70 \%$ of the hemorrhage); furthermore, some centers are not facilitated with on-site El department.

As the results of meta-analysis above, it took significantly longer operation time of El (PP: $0.92 \pm 0.20$ hours VS El: $1.25 \pm 0.60$ hours). This may require the availability of specialized equipment and well-trained radiologists, meanwhile take some lengthy steps[24] consisting of setting up an angiographic suite, scanning the angiography, finding out the crime vessels of bleeding, and conducting embolization or occlusion.

\section{The mortality.}

Despite advances in trauma care, cases of hemodynamically unstable pelvic fractures still have the high mortality rate of $30 \%-40 \%[44]$. Hemorrhage from the presacral venous plexus, and the large bulk of cancellous bone, comprise $60 \%-85 \%$ of the bleeding source[45]. Our study demonstrated that PP had significantly lower mortality rate due to uncontrolled hemorrhage in the acute phase with $11.1 \%$ (50/449) vs. 20.1\% (97/482) for PP and El, respectively. PP may be a direct solution to stop the bleeding through compression hemostasis and exogenous coagulation mechanism. Regarding mortality due to sepsis, ARDS and MOF, we did not observe a significant reduction difference between the PP and El groups.

\section{The preference of PP, AE or REBOA.}

In 1926, Logothetopulos first described PP[15]; however, it was rarely used in emergency for years and almost had disappeared from the scene. PP was brought about again by Pohlmann T. et al. in Germany decades ago and was originally adopted by the Denver group in the United States[44]. AE has been in long-term use by majority trauma centers since 1972. REBOA was first described for the treatment of hemorrhagic shock in the case of aorta abdominalis injury in 1954, and later was extent in the cases of the ruptured aortic aneurysm, abdominal trauma, gastrointestinal bleeding and postpartum hemorrhage[46]. Pieper A. et al. introduced this technique to treat pelvic fractures with life-threatening hemorrhage in France in 1998[47]. One hand, AE and REBOA recent years have been widely popularized for the non-negligible advantages of minimal invasiveness and local anesthesia intervention. On the other hand, it takes longer to wait for and manipulate AE and REBOA. Focusing on early angiography may delay the treatment of the associated injuries. Moreover, $\mathrm{AE}$ and REBOA have remarkable incidence rate of puncture point infection, pain, infarction, impotence, skin ulcer and necrosis[12, 37, 48].

Some centers are reluctant to prioritize PP, because it is an invasive procedure leading to a higher incidence of infection and requiring a second laparotomy for the removal of the packing $[15,18,49]$. In our systematic review, the morbidity of infection in packing group increased only mildly, without a significant difference. Therefore, PP is safe, quick, and simple treatment that is easy to master. Chao et al. also made a comparison of these procedures for hemodynamically unstable pelvic fractures in children and adolescents and considered packing as an easy and expeditious procedure against embolization[23]. Burlew proposed a secondary angioembolization was useful in ongoing pelvic bleeding after PP and external fixation[6]. The suggestion is clearly of no benefit for us to choose between PP and El, but to complement each other, and they are not competitive.

Unstable hemodynamics, especially when the bleeding source is unclear, requires quick and effective methods to control bleeding. Perhaps, the less timeconsuming PP would be the first choice while cooperating with other surgeries to stabilize multiple injuries. Besides bleeding from veins, fracture sites, small arteries and presacral venous plexus, PP is effective for hemorrhage control in open pelvic fractures[50]. AE is indicated for the suspicion of an injured pelvic artery that is actively bleeding[37]. REBOA, a temporary hemostatic measure to control combined multiple arterial bleedings or damage of main artery, could be used to transport the hemorrhagic shock patients to the operation suite[10,44].

Our meta-analysis had several limitations. The included studies, detailed data, and population sample were insufficient. Patients with unstable hemodynamic pelvic fractures usually have multiple sites' injuries, that are complex, changeable, unpredictable and different from each other[36]. So, it is difficult to conduct well-designed, blinded, randomized controlled trials, of which a proper systematic review and meta-analysis should firstly take advantage. This circumstance may lead to selection bias, reporting bias and literature bias. We settled for second best, and tried to identify as much studies as we can, including propensity score matching studies, multicenter studies, quasi-randomized clinical trials, observational cohort study and prospective cohort study to get an objective and scientific conclusion, relatively. These studies have little difference in design, implementation, all meeting the standard of the NOS. 


\section{Conclusion}

In summary, PP presented a significantly lower mortality due to uncontrolled pelvic bleeding in the acute phase, a shorter waiting and operating time, a possible decline of transfusion after intervention, and does not seem to increase the incidence of mortality due to complications. For most pelvic fracture patients with hemodynamical instability, we recommend that PP should be given high priority, especially when bleeding from the veins, internal pelvic vessels, and fractures. El should be regarded as a complementary treatment in cases of the consistent hypotension. AE is considered when bleeding from the pelvic arteries and hypotension persists after PP. REBOA is recommended when transporting patients with hemorrhagic shock and stopping fatal bleeding, such as main artery or multiple-source bleeding. Further studies with better design, larger sample size, and detail data, are looked forward to providing more solid evidence to verify superiority of the intervention.

\section{Abbreviations}

pelvic packing (PP) $₫$

endovascular intervention (EI)区

angiography-embolization (AE) $\mathbb{Q}$

resuscitative endovascular balloon occlusion of the aorta (REBOA)区

Injury Severity Score (ISS) $\bigotimes$

systolic blood pressure (SBP)囚

lactate (LA)凹

base deficiency (-BE)凶

Mean Difference (MD)凹

relative risk $(\mathrm{RR}) \rrbracket$

confidence intervals $(\mathrm{Cl}) \rrbracket$

Multiorgan failure (MOF) $\rrbracket$

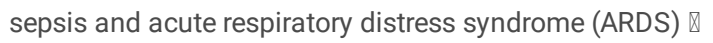

packed red blood cells (PRBC)区

\section{Declarations}

The meta analysis and systemic review meet the standands of Journal of Orthopaedic Trauma. All methods were performed in accordance with the relevant guidelines and regulations. Ethics approval and consent to participate has been obtained in our hosiptal. This manuscript does not need the approval from Institutional Regulation Board.

Consent to publish

The consent form state that the details/images/videos will be freely available on the internet and may be seen by the general public.

Availability of data and materials

Materials described in the manuscript, including all relevant raw data, will be freely available to any scientist wishing to use them for non-commercial purposes, without breaching participant confidentiality.

Competing interests

The authors declare that they have no conflict of interest.

Funding

This study was supported by Beijing Natural Science Foundation-Haidian original Innovation Joint Foundation囚L192016区.

This study was supported by National Natural Science Foundation of China खU21A20489『.

Authors' contributions

All authors have contributed significantly, and that all authors are in agreementwith the content of the manuscript, agree with your publish issues. Dong Zhang and Gong-zi Zhang carried out the search and content analysis and wrote the methodology and results section. Ye Peng, Shu-wei Zhang and Meng Li had 
participated in helping to compile and collect information on the manuscript. Lihai Zhang conceived the idea for the paper. Li-hai Zhang and Yv Zhang developed the methodology.

Acknowledgements

None.

\section{References}

1. Burlew, C.C., et al., Preperitoneal pelvic packing reduces mortality in patients with life-threatening hemorrhage due to unstable pelvic fractures. J Trauma Acute Care Surg, 2017. 82(2): p. 233-242.

2. Lin, S.S., et al., The effect of preperitoneal pelvic packing for hemodynamically unstable patients with pelvic fractures. Chin J Traumatol, 2021. 24(2): p. $100-103$.

3. Sandhu, J., et al., Pelvic Trauma: factors predicting arterial hemorrhage and the role of Angiography and preperitoneal pelvic packing. Eur Radiol, 2020. 30(11): p. 6376-6383.

4. Frassini, S., et al., Extraperitoneal packing in unstable blunt pelvic trauma: A single-center study. J Trauma Acute Care Surg, 2020. 88(5): p. 597-606.

5. Hundersmarck, D., et al., Pelvic packing and angio-embolization after blunt pelvic trauma: a retrospective 18-year analysis. Injury, 2021. 52(4): p. 946-955.

6. Burlew, C.C., et al., Preperitoneal pelvic packing/external fixation with secondary angioembolization: optimal care for life-threatening hemorrhage from unstable pelvic fractures. J Am Coll Surg, 2011. 212(4): p. 628 - 35; discussion 635-7.

7. Lustenberger, T., et al., The role of angio-embolization in the acute treatment concept of severe pelvic ring injuries. Injury, 2015. 46 Suppl 4: p. S33-8.

8. Cullinane, D.C., et al., Eastern Association for the Surgery of Trauma practice management guidelines for hemorrhage in pelvic fracture-update and systematic review. J Trauma, 2011. 71(6): p. 1850-68.

9. Copp, J. and J.G. Eastman, Novel resuscitation strategies in patients with a pelvic fracture. Injury, 2020.

10. O'Connell, K.M., et al., Balloons up: shorter time to angioembolization is associated with reduced mortality in patients with shock and complex pelvic fractures (original study). Trauma Surg Acute Care Open, 2021. 6(1): p. e000663.

11. Cherry, R.A., et al., Intraoperative angioembolization in the management of pelvic-fracture related hemodynamic instability. J Trauma Manag Outcomes, 2011. 5: p. 6.

12. Vaidya, R., et al., Angiography and Embolization in the Management of Bleeding Pelvic Fractures. J Am Acad Orthop Surg, 2018. 26(4): p. e68-e76.

13. Tanizaki, S., et al., Early embolization without external fixation in pelvic trauma. Am J Emerg Med, 2012. 30(2): p. 342-6.

14. Blondeau, B., et al., Variability in pelvic packing practices for hemodynamically unstable pelvic fractures at US level 1 trauma centers. Patient Saf Surg, 2019. 13: p. 3.

15. Filiberto, D.M. and A.D. Fox, Preperitoneal pelvic packing: Technique and outcomes. Int J Surg, 2016. 33(Pt B): p. $222-224$.

16. Al-Thani, H., et al., Utility of Angioembolization in Patients with Abdominal and Pelvic Traumatic Bleeding: Descriptive Observational Analysis from a Level 1 Trauma Center. Ther Clin Risk Manag, 2021. 17: p. 333-343.

17. Katayama, Y., et al., Pelvic angiography is effective for emergency pediatric patients with pelvic fractures: a propensity-score-matching study with a nationwide trauma registry in Japan. Eur J Trauma Emerg Surg, 2021. 47(2): p. 515-521.

18. Suzuki, T., W.R. Smith, and E.E. Moore, Pelvic packing or angiography: competitive or complementary? Injury, 2009. 40(4): p. 343-53.

19. Muntasar, A.E., et al., Effect of angioembolisation versus surgical packing on mortality in traumatic pelvic haemorrhage: A systematic review and metaanalysis. World J Emerg Med, 2018. 9(2): p. 85-92.

20. Siegmeth, A., et al., [Associated injuries in severe pelvic trauma]. Unfallchirurg, 2000. 103(7): p. 572-81.

21. Tai, D.K., et al., Retroperitoneal pelvic packing in the management of hemodynamically unstable pelvic fractures: a level I trauma center experience. J Trauma, 2011. 71(4): p. E79-86.

22. Osborn, P.M., et al., Direct retroperitoneal pelvic packing versus pelvic angiography: A comparison of two management protocols for haemodynamically unstable pelvic fractures. Injury, 2009. 40(1): p. 54-60.

23. Chao, N.S., et al., Retroperitoneal pelvic packing for haemodynamically unstable pelvic fractures in children and adolescents: a level-one trauma-centre experience. J Pediatr Surg, 2012. 47(12): p. 2244-50.

24. Cheng, M., et al., Improvement in institutional protocols leads to decreased mortality in patients with haemodynamically unstable pelvic fractures. Emerg Med J, 2015. 32(3): p. 214-20.

25. Li, Q., et al., Retroperitoneal packing or angioembolization for haemorrhage control of pelvic fractures-Quasi-randomized clinical trial of 56 haemodynamically unstable patients with Injury Severity Score $\geq 33$. Injury, 2016. 47(2): p. 395-401.

26. Jang, J.Y., et al., Preperitoneal pelvic packing in patients with hemodynamic instability due to severe pelvic fracture: early experience in a Korean trauma center. Scand J Trauma Resusc Emerg Med, 2016. 24: p. 3.

27. Chiara, O., et al., Efficacy of extra-peritoneal pelvic packing in hemodynamically unstable pelvic fractures, a Propensity Score Analysis. World J Emerg Surg, 2016. 11: p. 22.

28. Hsu, J.M., S. Yadev, and S. Faraj, Controlling hemorrhage in exsanguinating pelvic fractures: Utility of extraperitoneal pelvic packing as a damage control procedure. Int J Crit IIIn Inj Sci, 2016. 6(3): p. 148-152.

Page $8 / 16$ 
29. Froberg, L., et al., Mortality in trauma patients with active arterial bleeding managed by embolization or surgical packing: An observational cohort study of 66 patients. J Emerg Trauma Shock, 2016. 9(3): p. 107-14.

30. Shim, H., et al., Effectiveness and postoperative wound infection of preperitoneal pelvic packing in patients with hemodynamic instability caused by pelvic fracture. PLoS One, 2018. 13(11): p. e0206991.

31. Mikdad, S., et al., Pre-peritoneal pelvic packing for early hemorrhage control reduces mortality compared to resuscitative endovascular balloon occlusion of the aorta in severe blunt pelvic trauma patients: A nationwide analysis. Injury, 2020. 51(8): p. 1834-1839.

32. Asmar, S., et al., Resuscitative Endovascular Balloon Occlusion of the Aorta vs Pre-Peritoneal Packing in Patients with Pelvic Fracture. J Am Coll Surg, 2021. 232(1): p. 17-26.e2.

33. Frassini, S., et al., Emergency Management of Pelvic Bleeding. J Clin Med, 2021. 10(1).

34. Marmor, M., et al., Management of Pelvic Ring Injury Patients With Hemodynamic Instability. Front Surg, 2020. 7: p. 588845.

35. Agri, F., et al., Association of pelvic fracture patterns, pelvic binder use and arterial angio-embolization with transfusion requirements and mortality rates; a 7-year retrospective cohort study. BMC Surg, 2017. 17(1): p. 104.

36. Hak, D.J., W.R. Smith, and T. Suzuki, Management of hemorrhage in life-threatening pelvic fracture. J Am Acad Orthop Surg, $2009.17(7)$ : p. 447-57.

37. Lustenberger, T., et al., Secondary Angio-Embolization After Emergent Pelvic Stabilization and Pelvic Packing Is a Safe Option for Patients With Persistent Hemorrhage From Unstable Pelvic Ring Injuries. Front Surg, 2020. 7: p. 601140.

38. Moon, S.N., J.S. Pyo, and W.S. Kang, Accuracy of Contrast Extravasation on Computed Tomography for Diagnosing Severe Pelvic Hemorrhage in Pelvic Trauma Patients: A Meta-Analysis. Medicina (Kaunas), 2021. 57(1).

39. Lee, H.J., et al., The size of pelvic hematoma can be a predictive factor for angioembolization in hemodynamically unstable pelvic trauma. Ann Surg Treat Res, 2020. 98(3): p. 146-152.

40. Wong, Y.C., et al., Mortality after successful transcatheter arterial embolization in patients with unstable pelvic fractures: rate of blood transfusion as a predictive factor. J Trauma, 2000. 49(1): p. 71-5.

41. Smith, W., et al., Early predictors of mortality in hemodynamically unstable pelvis fractures. J Orthop Trauma, 2007. 21(1): p. 31-7.

42. Jang, J.Y., et al., Improvement of outcomes in patients with pelvic fractures and hemodynamic instability after the establishment of a Korean regional trauma center. Eur J Trauma Emerg Surg, 2019. 45(1): p. 107-113.

43. White, C.E., J.R. Hsu, and J.B. Holcomb, Haemodynamically unstable pelvic fractures. Injury, 2009. 40(10): p. 1023-30.

44. Magee, G.A., C.J. Fox, and E.E. Moore, Resuscitative endovascular balloon occlusion of the aorta in pelvic ring fractures: The Denver Health protocol. Injury, 2020.

45. Tosounidis, T.I. and P.V. Giannoudis, Pelvic fractures presenting with haemodynamic instability: treatment options and outcomes. Surgeon, 2013. 11(6): p. 344-51.

46. Martinelli, T., et al., Intra-aortic balloon occlusion to salvage patients with life-threatening hemorrhagic shocks from pelvic fractures. J Trauma, 2010. 68(4): p. 942-8.

47. Pieper, A., et al., Resuscitative endovascular balloon occlusion of the aorta for pelvic blunt trauma and life-threatening hemorrhage: $A$ 20-year experience in a Level I trauma center. J Trauma Acute Care Surg, 2018. 84(3): p. 449-453.

48. van der Vlies, C.H., et al., Failure rate and complications of angiography and embolization for abdominal and pelvic trauma. J Trauma Acute Care Surg, 2012. 73(5): p. 1208-12.

49. Gaski, I.A., et al., Reduced need for extraperitoneal pelvic packing for severe pelvic fractures is associated with improved resuscitation strategies. J Trauma Acute Care Surg, 2016. 81(4): p. 644-51.

50. Moskowitz, E.E., et al., Preperitoneal pelvic packing is effective for hemorrhage control in open pelvic fractures. Am J Surg, 2018. 215(4): p. 675-677.

\section{Tables}

Table 1 The scores of the studies according to The Newcastle - Ottawa quality assessment scale 
Osborn Tai, Chao Cheng Li Jang Chiara Hsu Froberg Shim Sandhu Hundersmarck

\begin{tabular}{|c|c|c|c|c|c|c|c|c|c|c|c|c|c|}
\hline & & $\begin{array}{l}\text { Osborn } \\
\text { P. M. } \\
\text { [22] }\end{array}$ & $\begin{array}{l}\text { Tai, } \\
\text { D.K } \\
{[21]}\end{array}$ & $\begin{array}{l}\text { Chao } \\
\text { N. } \\
{[23]}\end{array}$ & $\begin{array}{l}\text { Cheng } \\
\text { M. } \\
{[24]}\end{array}$ & $\begin{array}{l}\mathrm{Li} \\
\mathrm{Q} . \mathrm{H} . \\
{[25]}\end{array}$ & $\begin{array}{l}\text { Jang } \\
\text { J.Y. } \\
\text { [26] }\end{array}$ & $\begin{array}{l}\text { Chiara } \\
\text { O. } \\
\text { [27] }\end{array}$ & $\begin{array}{l}\text { Hsu } \\
\text { J.M. } \\
{[28]}\end{array}$ & $\begin{array}{l}\text { Froberg } \\
\text { L. [29] }\end{array}$ & $\begin{array}{l}\text { Shim } \\
\text { H.J. } \\
\text { [30] }\end{array}$ & $\begin{array}{l}\text { Sandhu } \\
\text { J. [3] }\end{array}$ & $\begin{array}{l}\text { Hundersmarck } \\
\text { D. [5] }\end{array}$ \\
\hline \multirow[t]{4}{*}{ Selection } & $\begin{array}{l}\text { Representativeness } \\
\text { of the exposed } \\
\text { cohort }\end{array}$ & 1 & 1 & 1 & 1 & 1 & 1 & 1 & 1 & 1 & 1 & 1 & 1 \\
\hline & $\begin{array}{l}\text { Selection of the } \\
\text { non-exposed } \\
\text { cohort }\end{array}$ & 1 & 1 & 0 & 1 & 1 & 1 & 1 & 1 & 1 & 1 & 1 & 1 \\
\hline & $\begin{array}{l}\text { Ascertainment of } \\
\text { exposure }\end{array}$ & 1 & 1 & 1 & 1 & 1 & 1 & 1 & 1 & 1 & 1 & 1 & 1 \\
\hline & $\begin{array}{l}\text { Demonstration that } \\
\text { outcome of interest } \\
\text { was not present at } \\
\text { start of study }\end{array}$ & 1 & 1 & 1 & 1 & 1 & 1 & 1 & 1 & 1 & 1 & 1 & 1 \\
\hline Comparability & $\begin{array}{l}\text { Comparability of } \\
\text { cohorts on the } \\
\text { basis of the design } \\
\text { or analysis }\end{array}$ & 1 & 2 & 1 & 2 & 1 & 1 & 2 & 2 & 2 & 1 & 1 & 2 \\
\hline \multirow[t]{3}{*}{ Outcome } & $\begin{array}{l}\text { Assessment of } \\
\text { outcome }\end{array}$ & 1 & 1 & 1 & 1 & 1 & 1 & 1 & 1 & 1 & 1 & 1 & 1 \\
\hline & $\begin{array}{l}\text { Was follow-up long } \\
\text { enough for } \\
\text { outcomes to occur }\end{array}$ & 0 & 0 & 1 & 0 & 0 & 0 & 0 & 0 & 0 & 0 & 0 & 0 \\
\hline & $\begin{array}{l}\text { Adequacy of follow } \\
\text { up of cohorts }\end{array}$ & 1 & 1 & 1 & 1 & 1 & 1 & 1 & 1 & 1 & 1 & 1 & 1 \\
\hline Total score & & 7 & 8 & 7 & 8 & 7 & 7 & 8 & 8 & 8 & 7 & 7 & 8 \\
\hline
\end{tabular}

Table 2 Details of studies included in the review and meta-analysis 


\begin{tabular}{|c|c|c|c|c|c|c|c|c|c|c|}
\hline & & $\begin{array}{l}\text { Osbom P. M. } \\
\text { [22] }\end{array}$ & $\begin{array}{l}\text { Tai, D.K } \\
\text { [21] }\end{array}$ & $\begin{array}{l}\text { Chao N. } \\
\text { [23] }\end{array}$ & $\begin{array}{l}\text { Cheng M. } \\
\text { [24] }\end{array}$ & $\begin{array}{l}\text { Li Q.H. } \\
\text { [25] }\end{array}$ & $\begin{array}{l}\text { Jang J.Y. } \\
\text { [26] }\end{array}$ & $\begin{array}{l}\text { Chiara } 0 . \\
\text { [27] }\end{array}$ & $\begin{array}{l}\text { Hsu J.M. } \\
\text { [28] }\end{array}$ & $\begin{array}{l}\mathrm{F} / \\
{[2}\end{array}$ \\
\hline \multicolumn{2}{|l|}{ Publication year } & 2009 & 2011 & 2012 & 2015 & 2015 & 2016 & 2016 & 2016 & 21 \\
\hline \multicolumn{2}{|l|}{ Study type } & $\begin{array}{l}\text { retrospective } \\
\text { cohort study }\end{array}$ & $\begin{array}{l}\text { retrospective } \\
\text { cohort study }\end{array}$ & $\begin{array}{l}\text { retrospective } \\
\text { cohort study }\end{array}$ & $\begin{array}{l}\text { retrospective } \\
\text { cohort study }\end{array}$ & $\begin{array}{l}\text { quasi- } \\
\text { randomized } \\
\text { clinical trial }\end{array}$ & $\begin{array}{l}\text { retrospective } \\
\text { cohort study }\end{array}$ & 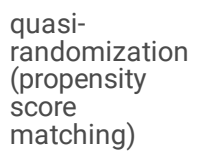 & $\begin{array}{l}\text { prospective } \\
\text { cohort } \\
\text { study }\end{array}$ & $\begin{array}{l}\text { ol } \\
\mathrm{cc}\end{array}$ \\
\hline \multicolumn{2}{|l|}{ Study period } & $\begin{array}{l}1998.04- \\
2006.06\end{array}$ & $\begin{array}{l}2007.06- \\
2009.12\end{array}$ & $2004-2011$ & $\begin{array}{l}1996.01- \\
2011.09\end{array}$ & $\begin{array}{l}2003.02- \\
2013.02\end{array}$ & $\begin{array}{l}2012.01- \\
2015.05\end{array}$ & $\begin{array}{l}2002.10- \\
2013.12\end{array}$ & $\begin{array}{l}2011.09- \\
2014.05\end{array}$ & $\begin{array}{l}21 \\
21\end{array}$ \\
\hline \multicolumn{2}{|l|}{ Quality (NOS) } & 7 & 8 & 7 & 8 & 8 & 7 & 8 & 8 & 8 \\
\hline \multicolumn{2}{|c|}{$\begin{array}{l}\text { Quantity of enrolled } \\
\text { patients (n) }\end{array}$} & 40 & 24 & 7 & 125 & 56 & 30 & 50 & 24 & 61 \\
\hline \multicolumn{2}{|l|}{$\begin{array}{l}\text { Female gender } \\
\mathrm{n} \% \text { pts }\end{array}$} & $\mathrm{nm}$ & $9(37.5 \%)$ & $2(28.6 \%)$ & $55(44 \%)$ & $24(42.9 \%)$ & $8(26.7 \%)$ & $\mathrm{nm}$ & $4(16.7 \%)$ & 21 \\
\hline \multirow{2}{*}{$\begin{array}{l}\text { Operation type } \\
\text { n囚\% pts囚 }\end{array}$} & PP & $20(50 \%)$ & $11(45.8 \%)$ & $5(71.4 \%)$ & $49(39.2 \%)$ & 29 (51.8\%) & $14(46.7 \%)$ & $25(50 \%)$ & $14(58.3 \%)$ & $3 !$ \\
\hline & El & $20(50 \%)$ & $13(54.2 \%)$ & $2(28.6 \%)$ & $76(60.8 \%)$ & $27(48.2 \%)$ & $16(53.3 \%)$ & $25(50 \%)$ & $10(41.7 \%)$ & 3 \\
\hline \multirow[t]{2}{*}{ Age (years) } & PP & $37.9 \pm 18.9$ & $51.2 \pm 19.0$ & $15.4 \pm 3.6$ & $45.4 \pm 21.0$ & $43 \pm 13$ & $59.7 \pm 15.0$ & $59.8 \pm 20.8$ & $49.9 \pm 17.5$ & $4:$ \\
\hline & $\mathrm{El}$ & $39.5 \pm 17.4$ & $44.8 \pm 24.7$ & $10.0 \pm 2.8$ & $46.8 \pm 21.4$ & $40 \pm 9$ & $60.9 \pm 22.1$ & $50.6 \pm 20.7$ & $60.3 \pm 23.5$ & 41 \\
\hline \multirow[t]{2}{*}{ ISS (scores) } & PP & $54.7 \pm 12.7$ & $40.0 \pm 12.5$ & $42.0 \pm 17.9$ & $40.1 \pm 14.2$ & $48 \pm 6$ & $38.8 \pm 8.3$ & $39.1 \pm 8.7$ & $32 \pm 6.7$ & 31 \\
\hline & El & $45.9 \pm 8.7$ & $42.3 \pm 18.8$ & $41.0 \pm 22.6$ & $45.0 \pm 15.7$ & $43 \pm 7$ & $32.2 \pm 4.9$ & $42.48 \pm 15.3$ & $23.8 \pm 12.7$ & 31 \\
\hline \multirow{2}{*}{$\begin{array}{l}\text { SBP on } \\
\text { admission } \\
\text { (mmH) }\end{array}$} & PP & $81.5 \pm 13.6$ & $99.0 \pm 40.9$ & $\mathrm{~nm}$ & $92.0 \pm 42.8$ & $\mathrm{~nm}$ & $94.6 \pm 25.1$ & $64.1 \pm 15.3$ & $74.2 \pm 22.3$ & $\mathrm{nI}$ \\
\hline & $\mathrm{El}$ & $75.8 \pm 11.7$ & $61.2 \pm 52.3$ & $\mathrm{~nm}$ & $99.1 \pm 46.8$ & $\mathrm{~nm}$ & $84.3 \pm 24.1$ & $\mathrm{~nm}$ & $84.3 \pm 16.2$ & $\mathrm{nI}$ \\
\hline \multirow{2}{*}{$\begin{array}{l}\text { Lactate } \\
(\mathrm{mmol} / \mathrm{L})\end{array}$} & PP & $5.3 \pm 2.4$ & $\mathrm{~nm}$ & $\mathrm{~nm}$ & $\mathrm{~nm}$ & $\mathrm{~nm}$ & $4.9 \pm 2.8$ & $5.18 \pm 2.55$ & $5.2 \pm 2.9$ & 3. \\
\hline & El & $4.9 \pm 1.5$ & $\mathrm{~nm}$ & $\mathrm{~nm}$ & $\mathrm{~nm}$ & $\mathrm{~nm}$ & $5.2 \pm 3.4$ & $5.80 \pm 3.38$ & $4.8 \pm 4.3$ & 3. \\
\hline \multirow{2}{*}{$\begin{array}{l}\text { Base deficit } \\
\text { (mmol/L) }\end{array}$} & PP & $12.7 \pm 3.6$ & $10.8 \pm 6.2$ & $\mathrm{~nm}$ & $\mathrm{~nm}$ & $\mathrm{~nm}$ & $\mathrm{~nm}$ & $4.33 \pm 3.78$ & $7.9 \pm 4.7$ & 4. \\
\hline & $\mathrm{El}$ & $13.2 \pm 4.1$ & $14.8 \pm 9.0$ & $\mathrm{~nm}$ & $\mathrm{~nm}$ & $\mathrm{~nm}$ & $\mathrm{~nm}$ & $4.88 \pm 3.38$ & $6.2 \pm 6.3$ & 5. \\
\hline \multirow{2}{*}{$\begin{array}{l}\text { Unstable } \\
\text { fracture type } \\
\text { n (\% pts) }\end{array}$} & PP & $13(65.0 \%)$ & $8(72.7 \%)$ & $\mathrm{nm}$ & $27(55.1 \%)$ & $16(55.2 \%)$ & $\mathrm{nm}$ & $18(72 \%)$ & $\mathrm{nm}$ & $\mathrm{nI}$ \\
\hline & El & $14(70 \%)$ & $7(53.8 \%)$ & $\mathrm{nm}$ & $51(67.1 \%)$ & $14(51.9 \%)$ & $\mathrm{nm}$ & $21(84 \%)$ & $\mathrm{nm}$ & $\mathrm{nI}$ \\
\hline \multirow{2}{*}{$\begin{array}{l}\text { Transfusion } \\
\text { preoperatively } \\
\text { (IU) }\end{array}$} & PP & 11.8 & $2.0 \pm 1.2$ & $\mathrm{~nm}$ & $11.76 \pm 16.27$ & $11.2 \pm 2.3$ & $17.0 \pm 14.2$ & $13 \pm 11$ & $3.7 \pm 3.2$ & 11 \\
\hline & El & 9.2 & $3.2 \pm 2.3$ & $\mathrm{~nm}$ & $9.36 \pm 11.23$ & $10.9 \pm 1.8$ & $11.3 \pm 6.5$ & $14.1 \pm 11$ & $6.6 \pm 3.4$ & $6:$ \\
\hline \multirow{2}{*}{$\begin{array}{l}\text { Hemoglobin } \\
\text { preoperatively } \\
\text { (g/dL) }\end{array}$} & PP & $\mathrm{nm}$ & $11.8 \pm 2.3$ & $\mathrm{~nm}$ & $7.37 \pm 2.16$ & $\mathrm{~nm}$ & $10.4 \pm 1.8$ & $\mathrm{~nm}$ & $\mathrm{~nm}$ & 7. \\
\hline & $\mathrm{El}$ & $\mathrm{nm}$ & $11.6 \pm 1.6$ & $\mathrm{~nm}$ & $7.98 \pm 2.44$ & $\mathrm{~nm}$ & $10.7 \pm 2.5$ & $\mathrm{~nm}$ & $\mathrm{~nm}$ & 7. \\
\hline \multirow{2}{*}{$\begin{array}{l}\text { SBP } \\
\text { postoperatively } \\
(\mathrm{mmHg})\end{array}$} & PP & $87.1 \pm 11.9$ & $\mathrm{~nm}$ & $\mathrm{~nm}$ & $\mathrm{~nm}$ & $\mathrm{~nm}$ & $\mathrm{~nm}$ & $105.5 \pm 16.5$ & 83 & $\mathrm{nI}$ \\
\hline & El & $87.1 \pm 21.1$ & $\mathrm{~nm}$ & $\mathrm{~nm}$ & $\mathrm{~nm}$ & $\mathrm{~nm}$ & $\mathrm{~nm}$ & $\mathrm{~nm}$ & $\mathrm{~nm}$ & nı \\
\hline \multirow{2}{*}{$\begin{array}{l}\text { Waiting time to } \\
\text { intervention } \\
\text { (h) }\end{array}$} & PP & 0.75 & $1.16 \pm 0.26$ & $\mathrm{~nm}$ & $2.89 \pm 4.44$ & $1.28 \pm 0.32$ & $0.92 \pm 0.45$ & $0.36 \pm 0.13$ & $1.12 \pm 0.92$ & $\mathrm{nI}$ \\
\hline & $\mathrm{El}$ & 2.17 & $1.03 \pm 0.56$ & $\mathrm{~nm}$ & $4.69 \pm 5.98$ & $1.70 \pm 0.45$ & $3.23 \pm 0.75$ & $0.31 \pm 0.16$ & $2.17 \pm 1.05$ & $\mathrm{nI}$ \\
\hline \multirow{2}{*}{$\begin{array}{l}\text { Operation time } \\
\text { of intervention } \\
\text { (h) }\end{array}$} & PP & $\mathrm{nm}$ & $1.31 \pm 0.39$ & $\mathrm{~nm}$ & $\mathrm{~nm}$ & $1.00 \pm 0.23$ & $\mathrm{~nm}$ & $\mathrm{~nm}$ & $\mathrm{~nm}$ & $\mathrm{nI}$ \\
\hline & $\mathrm{El}$ & $\mathrm{nm}$ & $2.32 \pm 1.58$ & $\mathrm{~nm}$ & $\mathrm{~nm}$ & $1.40 \pm 0.20$ & $\mathrm{~nm}$ & $\mathrm{~nm}$ & $\mathrm{~nm}$ & $\mathrm{nI}$ \\
\hline \multirow{2}{*}{$\begin{array}{l}\text { Transfusion in } \\
\text { first } 24 \mathrm{~h} \text { after } \\
\text { intervention } \\
\text { (IU) }\end{array}$} & PP & 6.9 & $9.0 \pm 8.0$ & $\mathrm{~nm}$ & $\mathrm{~nm}$ & $5.2 \pm 1.8$ & $\mathrm{~nm}$ & $\mathrm{~nm}$ & $12.6 \pm 9.5$ & $\mathrm{nI}$ \\
\hline & $\mathrm{El}$ & 10.1 & $5.0 \pm 4.4$ & $\mathrm{~nm}$ & $\mathrm{~nm}$ & $6.4 \pm 1.7$ & $\mathrm{~nm}$ & $\mathrm{~nm}$ & $11.3 \pm 2.3$ & $\mathrm{nI}$ \\
\hline \multirow{2}{*}{$\begin{array}{l}\text { Mortality due } \\
\text { to uncontrolled } \\
\text { hemorrhage } \\
n(\% \mathrm{pts})\end{array}$} & PP & $0(0)$ & $1(9.1 \%)$ & $1(20 \%)$ & $7(14.3 \%)$ & $0(0)$ & $2(14.3 \%)$ & $5(20 \%)$ & $1(7.1 \%)$ & $\mathrm{nI}$ \\
\hline & $\mathrm{El}$ & $2(10 \%)$ & $3(23.1 \%)$ & $1(50 \%)$ & $26(34.2 \%)$ & $2(7.4 \%)$ & $6(37.5 \%)$ & $13(52 \%)$ & $1(10 \%)$ & $\mathrm{nI}$ \\
\hline \multirow{2}{*}{$\begin{array}{l}\text { Mortality due } \\
\text { to other } \\
\text { complications } \\
\text { n (\% pts) }\end{array}$} & PP & $4(20 \%)$ & $3(27.3 \%)$ & $0 / 5(0)$ & $8(16.3 \%)$ & $4(13.8 \%)$ & $3(21.4 \%)$ & $2(8 \%)$ & $0(0)$ & $\mathrm{nI}$ \\
\hline & $\mathrm{El}$ & $4(20 \%)$ & $6(46.2 \%)$ & $0 / 2(0)$ & $6(7.9 \%)$ & $3(11.1 \%)$ & $0(0)$ & $0(0 \%)$ & $2(20 \%)$ & $\mathrm{nI}$ \\
\hline $\begin{array}{l}\text { Total mortality } \\
\text { n (\% pts) }\end{array}$ & PP & $4(20 \%)$ & $4(36.4 \%)$ & $1(20 \%)$ & $15(30.6 \%)$ & $4(13.8 \%)$ & $5(35.7 \%)$ & $7(28 \%)$ & $1(7.1 \%)$ & 91 \\
\hline
\end{tabular}


El $6(30 \%)$

$9(69.2 \%)$

$1(50 \%)$

$32(42.1 \%)$

$5(18.5 \%)$

$6(37.5 \%)$

$13(52 \%)$

$3(30 \%)$

pts: percentages, nm: not mentioned

\section{Figures}

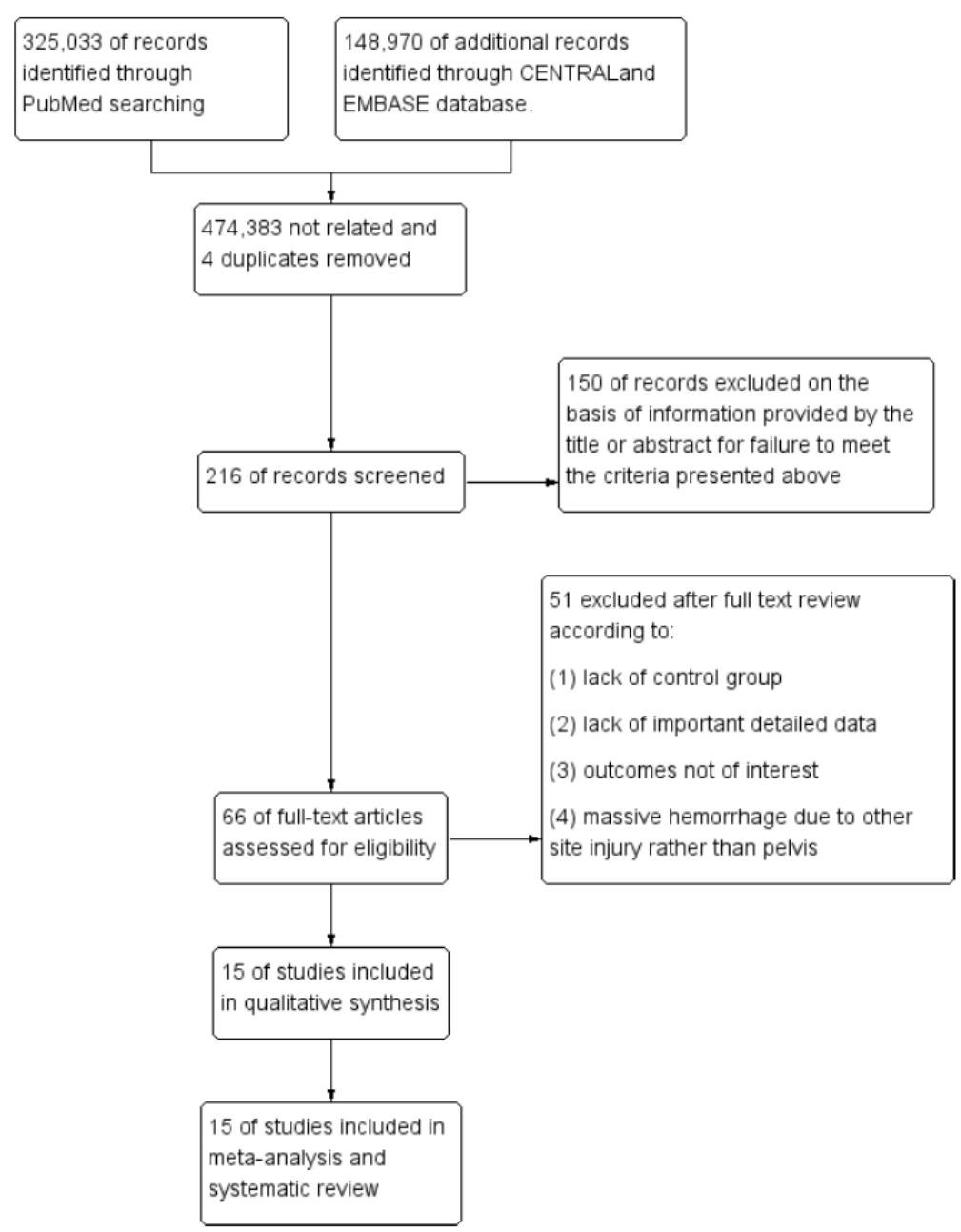

Figure 1

Study flow diagram of interventions managing hemodynamically unstable pelvic fractures

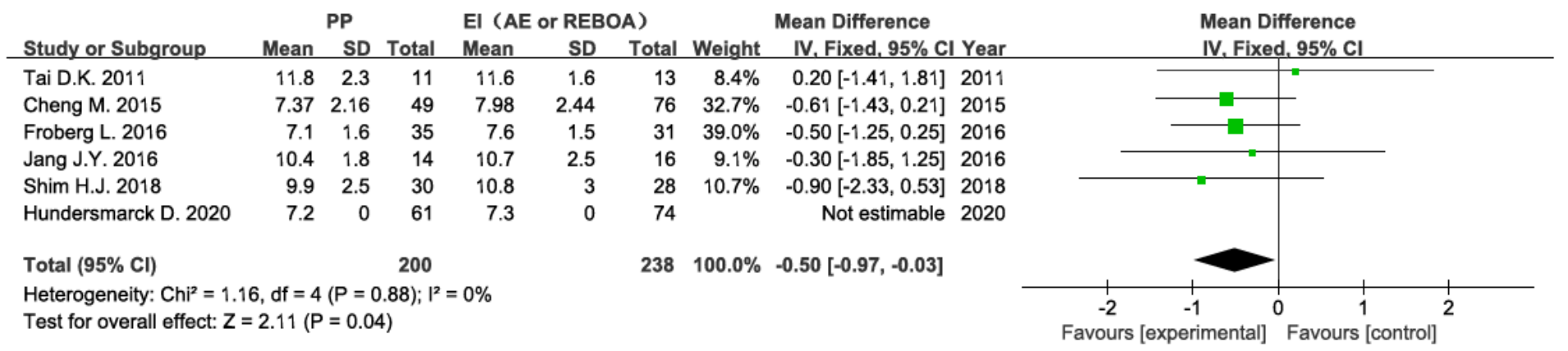

\section{Figure 2}

Table and forest plot illustrating the meta-analysis for preoperative hemoglobin upon admission. 


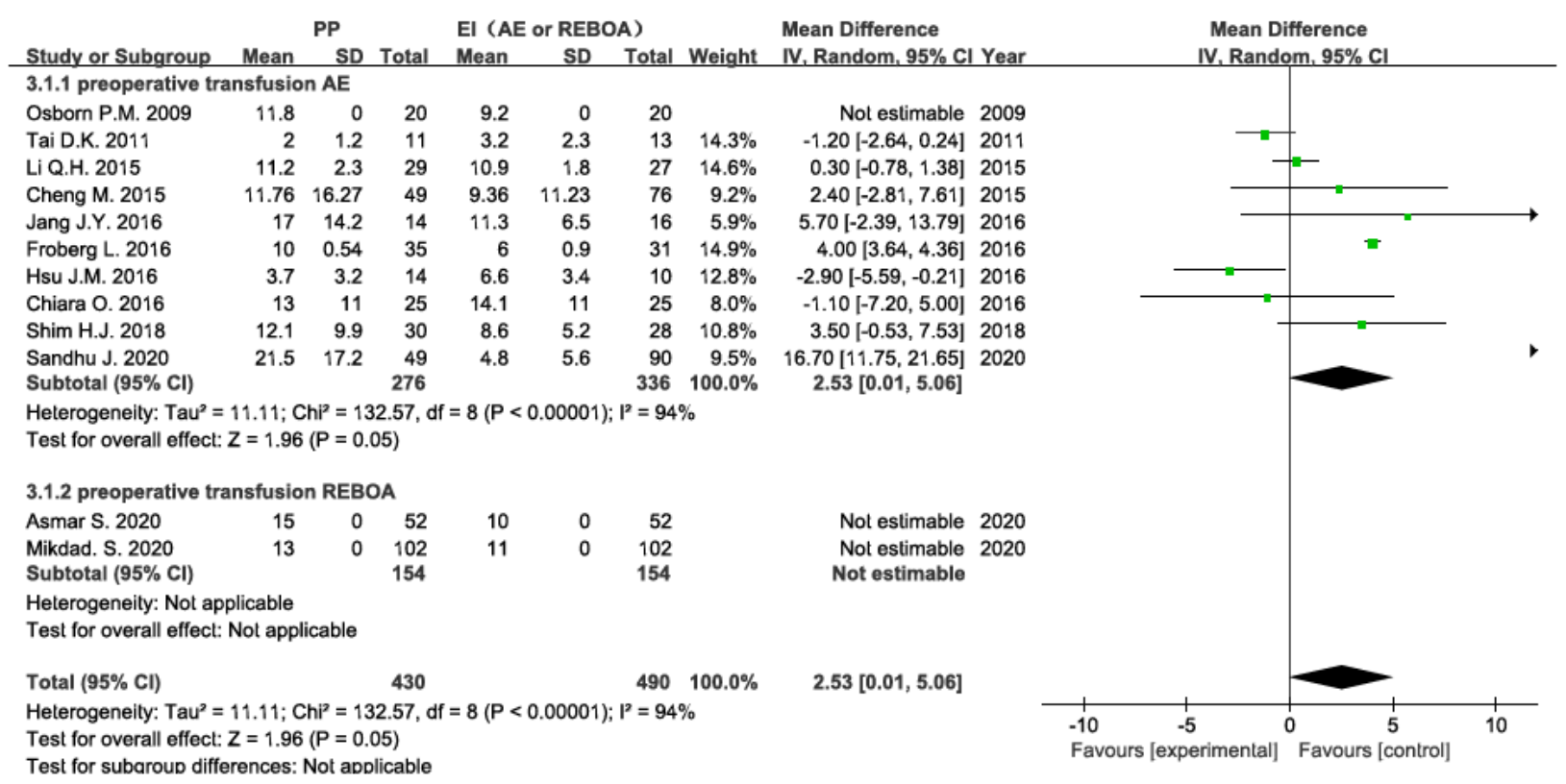

Figure 3

Table and forest plot illustrating the meta-analysis for transfusion before operation.

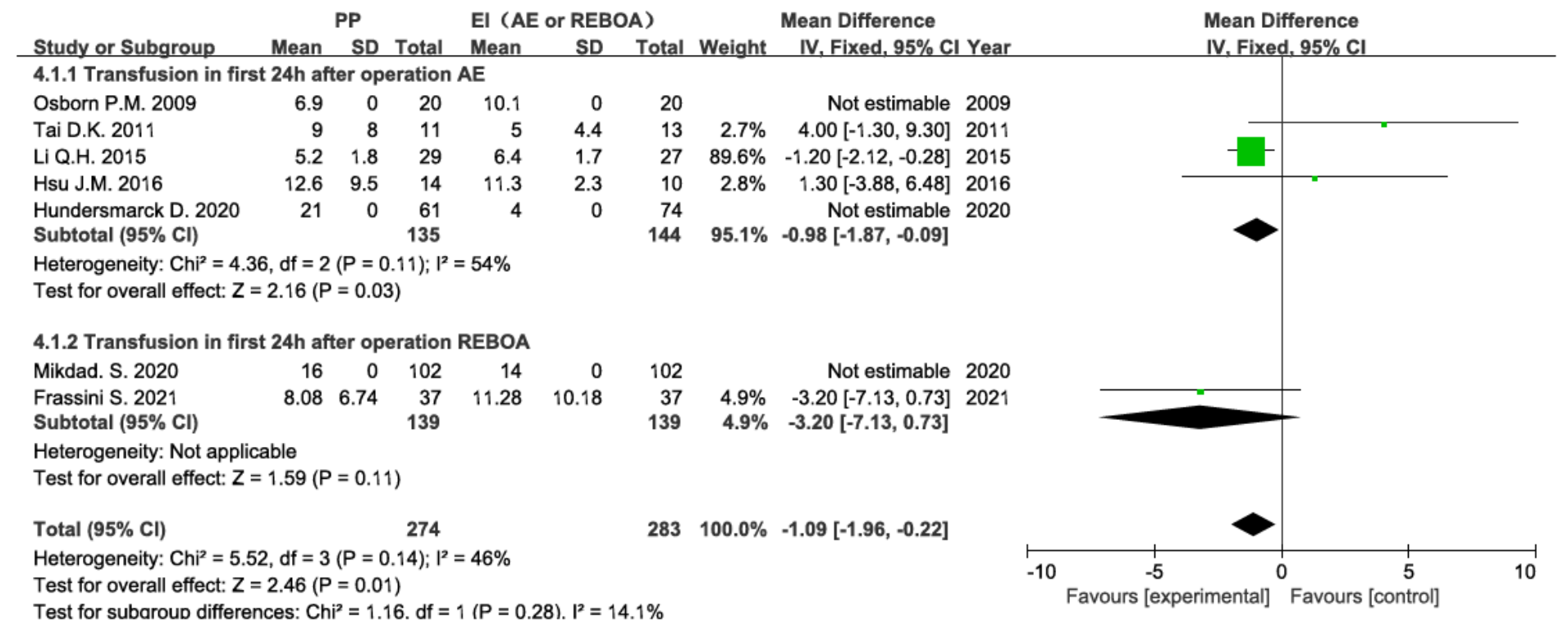

\section{Figure 4}

Table and forest plot illustrating the meta-analysis for transfusion after operation in the first $24 \mathrm{hs}$ 


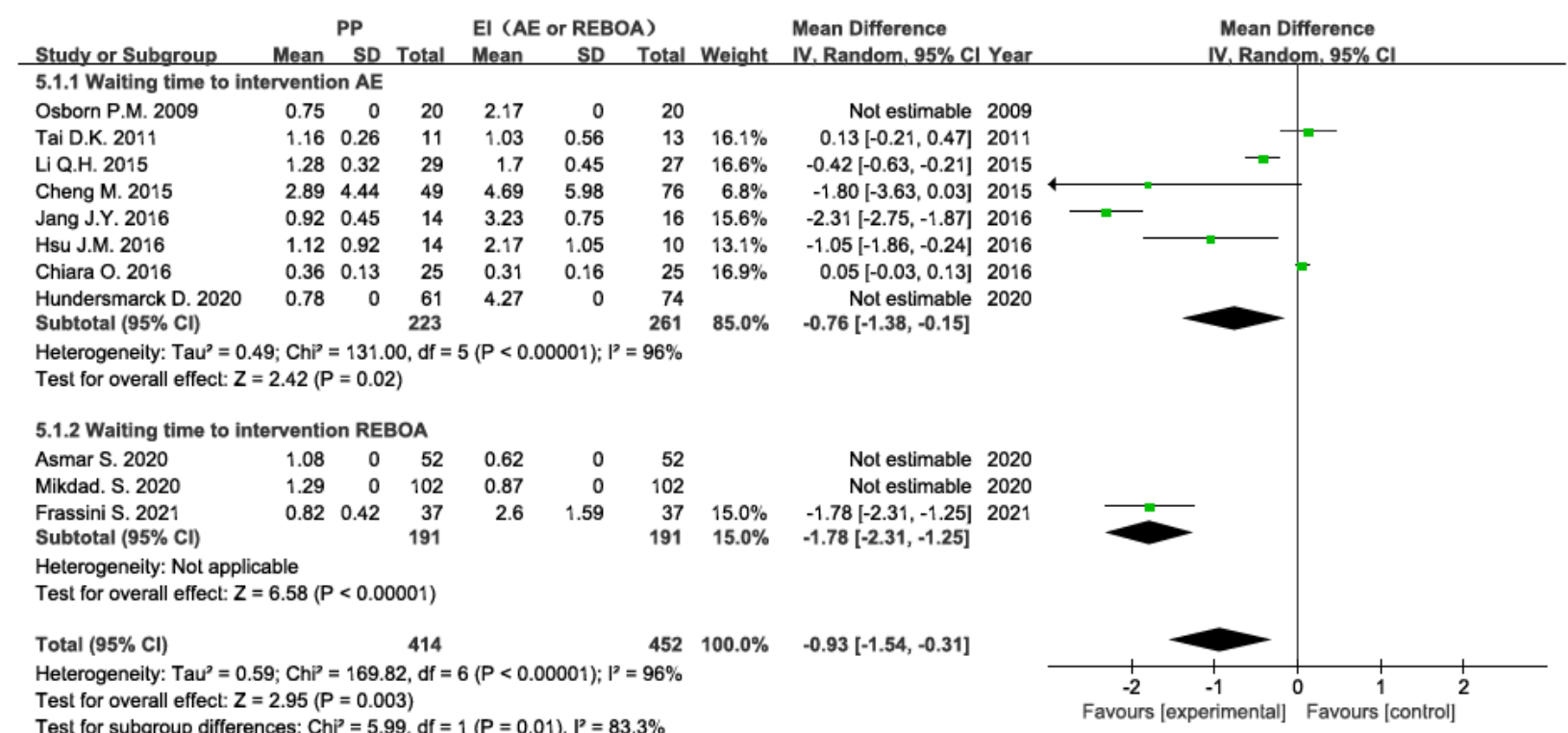

Figure 5

Table and forest plot illustrating the meta-analysis for waiting time to operation.

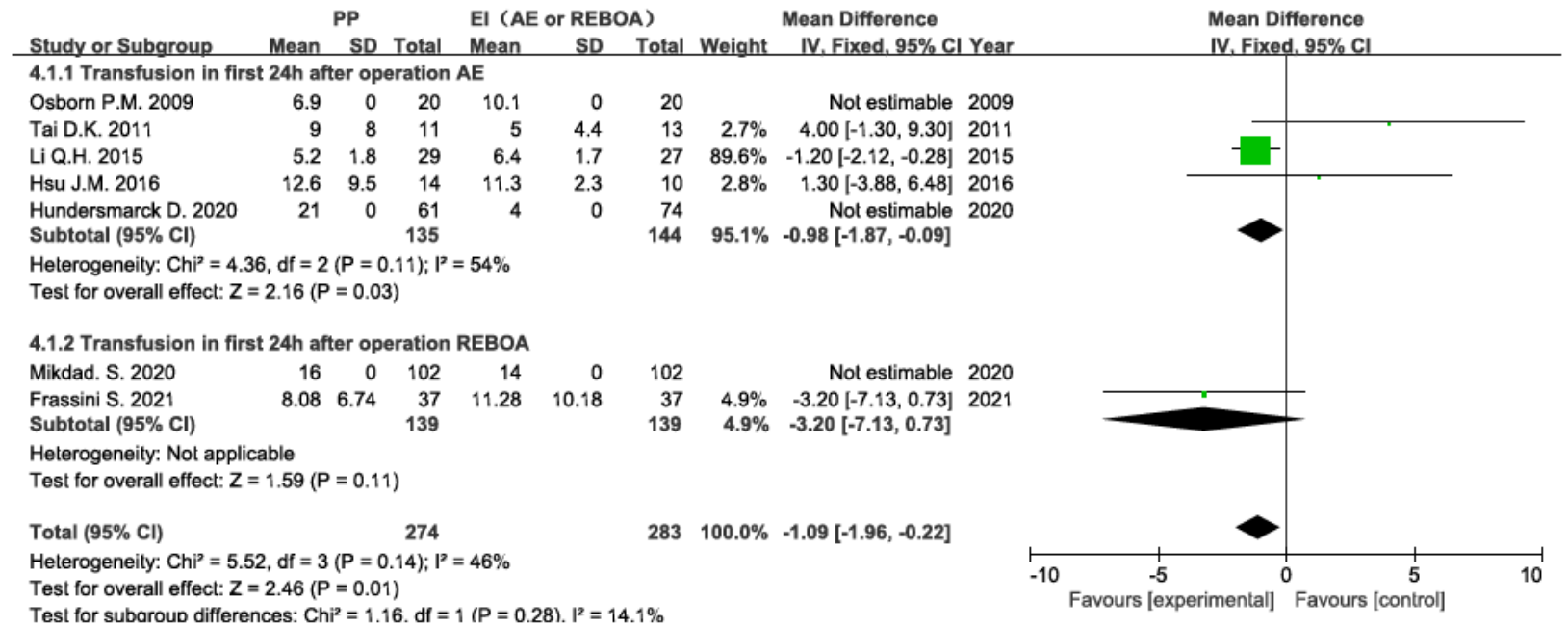

Figure 6

Table and forest plot illustrating the meta-analysis for operation time of intervention. 


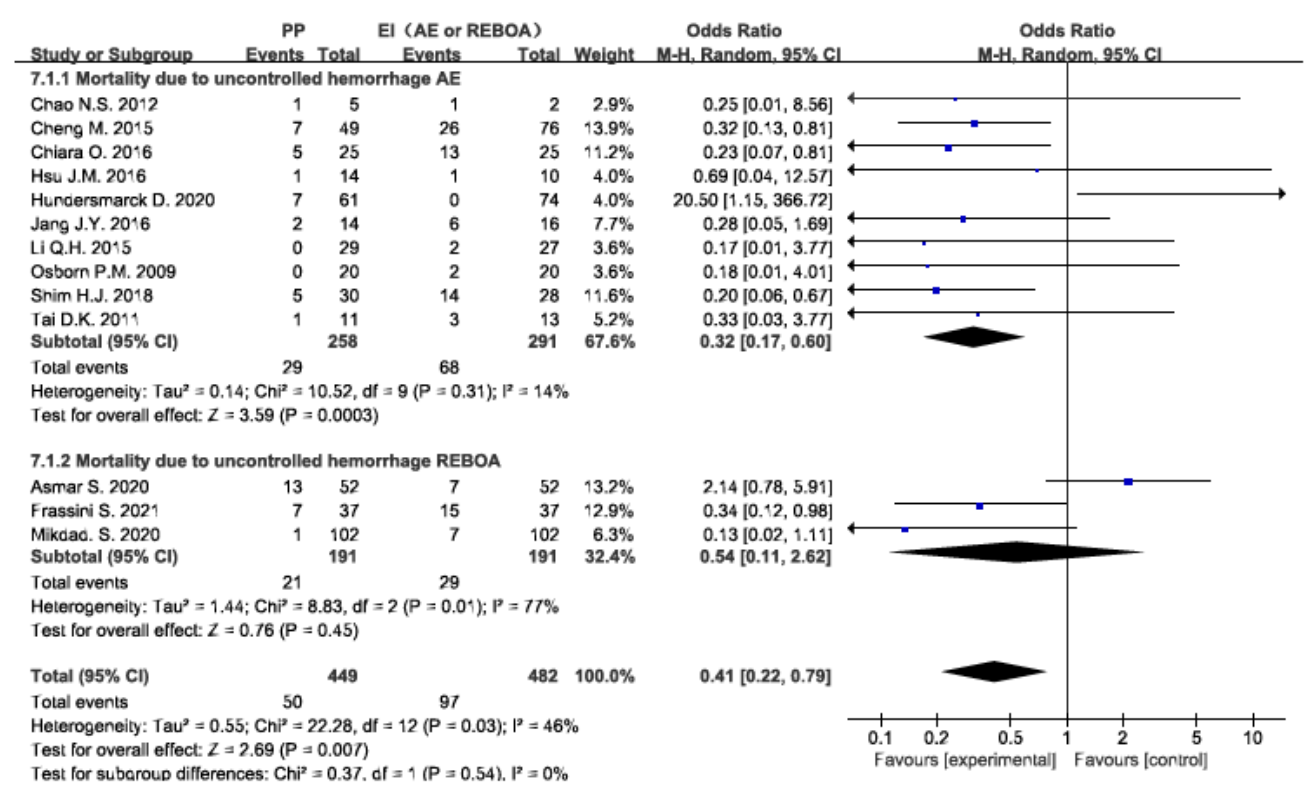

\section{Figure 7}

Table and forest plot illustrating the meta-analysis for mortality due to uncontrolled hemorrhage in the acute phase

PP

EI (AE or REBOA)

Odds Ratio

Odds Ratio

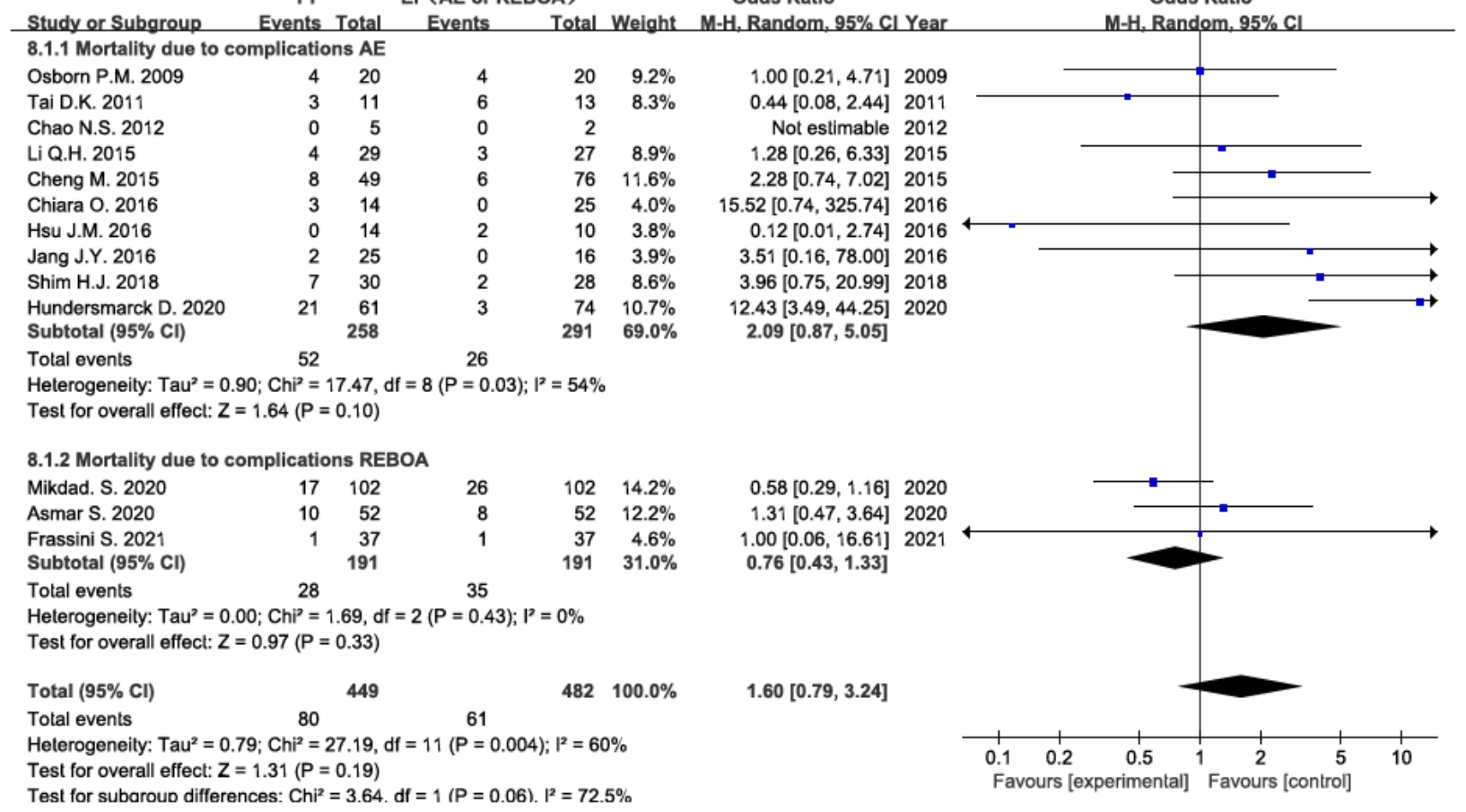

Figure 8

Table and forest plot illustrating the meta-analysis for mortality due to other complications (such as sepsis, MOF and ARDS) 


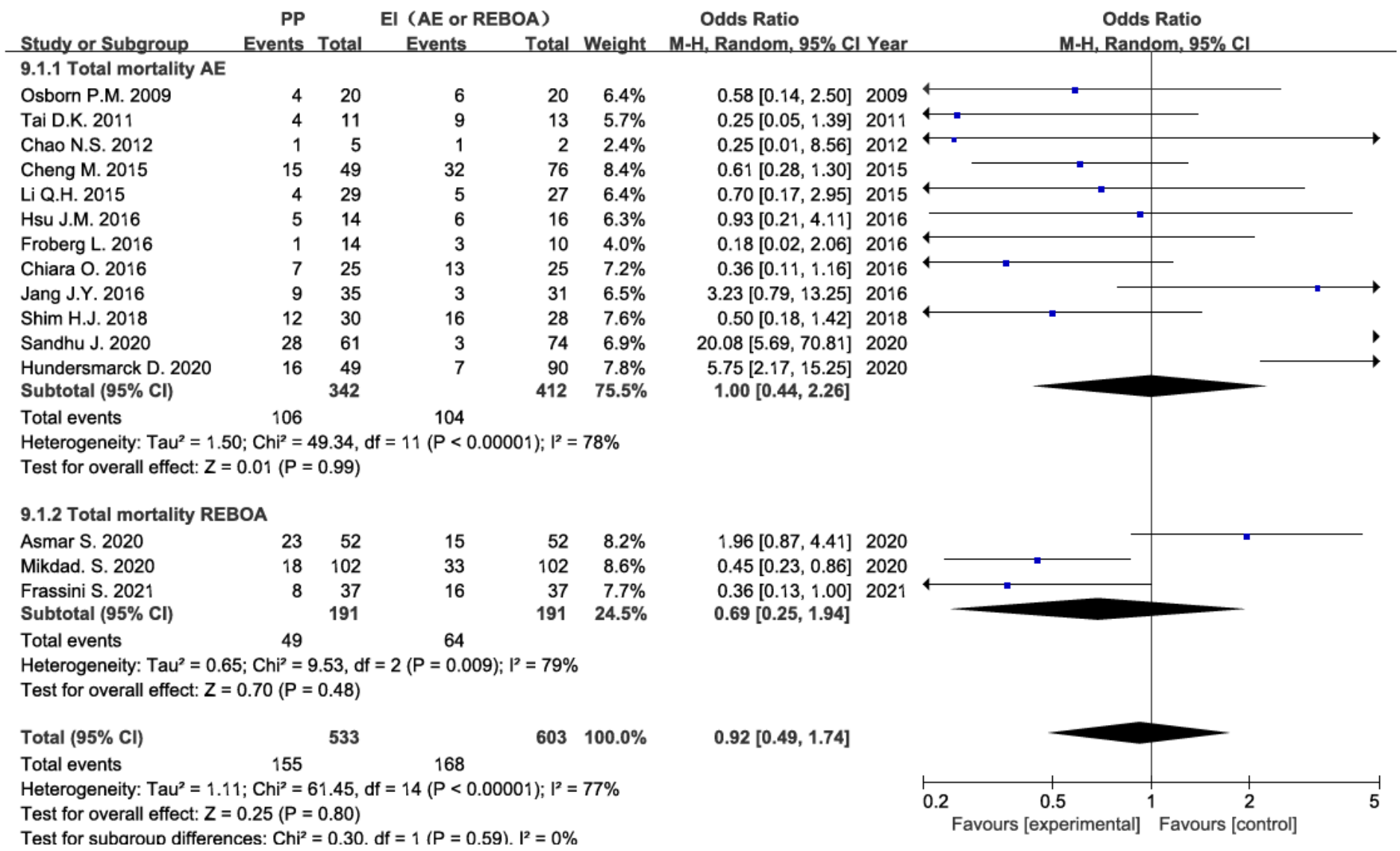

Figure 9

Table and forest plot illustrating the meta-analysis for total mortality

\section{Supplementary Files}

This is a list of supplementary files associated with this preprint. Click to download.

- PRISMAChecklist.pdf 